\title{
Validation and Reliability of the Chinese Version of the Miller Behavioral Style Scale
}

Qiqi Zhuo

The First Affiliated Hospital of Kunming Medical University https://orcid.org/0000-0002-2375-3369

Hongmin Liang

Department of Nursing,The First Affiliated Hospital of Kunming Medical University

Yangjuan Bai

Cardiology Department, The First Affiliated Hospital of Kunming Medical University

Qiulan Hu

ICU in Geriatric Department, The First Affiliated Hospital of Kunming Medical University

Ardani Latifah Hanum

Department of Nursing, The First Affiliated Hospital of Kunming Medical University

\section{Mingfang Yang}

Urology Department, The First Affiliated Hospital of Kunming Medical University

\section{Yanjiao Wang}

Psychiatric Department, The First Affiliated Hospital of Kunming Medical University

\section{Wei Wei}

Neurosurgery Department, The First Affiliated Hospital of Kunming Medical University

\section{Lan Ding}

General Surgery Department, The First Affiliated Hospital of Kunming Medical University

Fang Ma ( $\square$ rebeccamalei@126.com)

https://orcid.org/0000-0002-0784-6346

\section{Research}

Keywords: Health education, Psychometric properties, Information-seeking style

Posted Date: July 15th, 2020

DOI: https://doi.org/10.21203/rs.3.rs-41706/v1

License: () (i) This work is licensed under a Creative Commons Attribution 4.0 International License. Read Full License 


\section{Abstract}

Objectives: To test the psychometric properties of the Chinese version of Miller Behavioral Style Scale(C-MBSS).

Methods: The forward-back-translation procedure was adopted in the translation of the Miller Behavioral Style Scale. Content validity was assessed in a panel of experts. In a sample of 1343 individuals, reliability and construct validity were assessed using Cronbach's alpha coefficient and factor analysis. For exploratory factor analysis, parallel analysis was used to decide number of factors, principal axis factoring and direct oblimin rotation method were used to select factor. For confirmatory factor analysis, structural equation modelling was established to verify the extracted factor structure.

Results: The C-MBSS achieved conceptual and semantic equivalence with the original scale. The item content validity index(I-CVI) of each item ranged from 0.78 to 1 , and the averaging scale content validity index(S-CVI/ Ave) was 0.95 . The cronbach`s alpha coefficient for the scale and sub-scales were over 0.6. The exploratory factor analysis resulted in 2factor assumption for each hypothetical threat-evoking scenario. Confirmatory factor analysis provided confirmatory evidence for the second-order factor structure of 2-factor solution (Monitoring and Blunting) and demonstrated a good fit between theoretical model and data.

Conclusions: This study verified the psychometric properties of the C-MBSS and indicated that the C-MBSS can be used to identify individual's information-seeking style in Chinese population. With the use of the C-MBSS, health care professionals in China can deliver health education based on patients' information-seeking behavior, which can improve the effect of health education and patients' health outcomes.

\section{Introduction}

As a health promotion method, health education help improve people's knowledge of illness, develop their health behavior, increase individual's sense of responsibility for maintaining health and achieve fully informed consent by the providence of health care information [1-6]. It was reported that if patients were informed about any side effects, possible complications, and the way treatment might affect their daily life, they might establish healthy behaviors and improve self-efficacy $[7,8]$. Furthermore, patients can make the right decisions about treatment, correct their wrong beliefs, alleviate psychological comorbidities and thus enhancing their quality of live by being informed about appropriate, valid, and expert health care information [9]. Hence, health care information can also be therapeutic and many patients desire to be given more health-related risk and disease information [10].

Although several studies have documented the various positive impacts of health care information, it has also been evidenced that sometimes the wealth of information available to patients can be as dangerous as it is helpful [11-14]. Deyirmenjian et al. reported that for open-heart patients, the ones with more information providence showed higher levels of preoperative and postoperative anxiety compared with patients almost with no information giving [15]. Montazeri et al. found out that after giving cancer-related information to women in a waiting room at the breast cancer center, they became upset and anxiety [16]. Miller et al. mentioned that when women were exposed to cervical cancer risk information, they might catastrophize health dangers and felt intensely anxious and vulnerable [17]. Doherty-Torstrick et al. reported that for individuals with high illness anxiety, the search for medical information on the Internet made them experience more anxiety [18].

Miller proposed the "Blunting Hypothesis" based on Seligman's safety signal theory, which accounts for individual differences about preference for predictability("monitors") and preference for unpredictability("blunters") under threat [19]. In this theory individuals were categorized into two different coping styles based on their threat-related response: monitors(information seekers) or blunters (information avoiders). When encountering threat-related event, information seekers monitor information and amblifv cognitively and emotionally threats, whereas information avoiders avoid and Loading [MathJax]/jax/output/CommonHTML/jax.js

Page 2/16 
psychologically blunt such cues [20]. In health-related situations, high monitors prefer detailed health-related information and fare better when it is given, and they tend to perceived more risks and show great anxiety or distress when information is not readily available $[9,19]$. On the contrary, blunters do better with less information. They cope with aversive health events by distraction, and they tend to make themselves remove from further psychological awareness of disease and their anxiety may be increased when information is supplied too much [19]. Miller mentioned that when patients receive information which match their coping styles, they have better outcomes psychologically, behaviorally and physiologically $[21,22]$. It has been evidenced that once the information provided is consistent with individual's coping style, they will feel less anxious, suffer less complications after surgery, experience shorter hospital length of stay, improve adherence, and show more satisfaction with communication [23-25]. Therefore, patients' information-seeking styles need to be taken into consideration before providing health care information. The first step is to identify individual variations in information-seeking styles, which requires validated measures of individual information-seeking style preferences.

There exist several scales that can predict information-seeking styles, such as Sentence Completion Test, RepressionSensitization Scale, Schedule of Recent Experiences [20, 26, 27], among which the Miller Behavioral Style Scale (MBSS) shows good reliability as well as good discriminant and convergent validity compared with other scales. ${ }^{19}$ The MBSS is a reliable and validated scale, and by far the most extensively used scale for predicting information-seeking style [28-30]. Whether the original scale can be used in population from different social, ethical and cultural backgrounds needs further study. In addition, according to Rees's [29] literature review of the researches about the MBSS scale, Cronbach`salpha coefficient was rarely reported, and many of the research samples were recruited from students and the sample sizes were small, which limited the generalization of the scale. This study aims to examine the psychometric properties of the MBSS among individuals in Mainland China using a large sample size in medical and non-medical settings.

\section{Methods}

\section{Design}

A cross-sectional survey with a convenience sampling method was conducted from August to September 2019 in Yunnan Province, Southwest China. The MBSS can be used in different contexts (i.e., medical setting, worksite, academic context, community center, home setting), as well as across populations (i.e., individuals at-risk for disease, patients, and the healthy population). Our participants included university students, medical staff, patients receiving percutaneous coronary intervention and their caregivers, which could maximize the sample size and diversity. University students and medical staff got the Chinese version of MBSS (C-MBSS) via on line survey(wenjuanxing). Patients receiving percutaneous coronary intervention and their caregivers were given 15 minutes to fill in the written C-MBSS in the hospital placement before their surgery. The research was approved by the ethics committee of the hospital.

\section{Measures}

Miller Behavioral Style Scale (MBSS) assesses individuals in terms of their distinctive attentional processing styles or "behavioral signatures," by characterizing them into high versus low monitors in terms of how individuals process and effectively react to threat information. The scale consists of four hypothetical threat-evoking scenarios (1.fear of having dental work done; 2.kidnapped by a group of terrorist militants; 3 . in danger of losing the job; 4 . technical problems with the flight); each of which has eight corresponding potential coping responses, including 4 monitoring responses(e.g., "I would watch all the dentist's movements and listen for the sound of the drill") and 4 blunting responses(e.g., "I would try to think about pleasant memories"). There are totally 16 monitoring responses and 16 blunting responses. With the permission of the original author of the scale, a 5-point Likert scale ranging from 1 "strongly unlikely" to 5 "strongly likely" was used for items scoring instead of the original dichotomous one, which allowed participants to give more varied and

Loading [MathJax]/jax/output/CommonHTML/jax.js wers [29, 31]. The participants were asked to indicate the score that would 
apply to them for each response [20]. Therefore, the total Monitoring ("M") score ranges from 16-80 and the total Blunting ("B") score ranges from 16-80. Beyond that, demographic information including gender, age, nationality, occupation, educational background, diagnosis, type of operation etc. were also collected using a self-made demographic questionnaire.

\section{Translation procedure}

With the written permission of the original author to use the MBSS, we translated the scale followed the forward-backtranslation procedure [32]. Firstly, two native Chinese speakers with proficiency in English translated the scale into Mandarin Chinese. One translator is a nurse with master degree who studied in Ireland for one year; the other is an English linguistics scientist who had experiences of staying in London for two years. The two translated versions were selected and merged into a single version by the two translators. Secondly, two bilingual translators translated the Chinese version back to English. Translators were Chinese scholars who had worked in the USA for 10 years and were unaware of the research. The two English versions were selected and merged into a single version by the two translators. Semantic equivalence was conducted between the translation and the original version by an English native speaker. Thirdly, an expert committee composed of a psychiatrist, an English linguistics scientist and two nurses conducted cultural adaptation of the Chinese version to form a pre-final scale.

The readability and comprehensiveness of the scale were assessed in a convenience sample of 20 patients with coronary heart disease and 20 healthy university students. For the pilot test, after reading the four hypothetical stress-evoking scenarios of the C-MBSS, the participants were asked to tick the responses which they would most likely to do using a Likert 5-point scale(from strongly unlikely to strongly likely). Then a face-to-face interview was conducted to all participants to get their opinion about scale. According to the interview, all participants stated that they could understand the scenarios and responses easily, and it took approximately 10-15 minutes to finish the scale.

\section{Content validity}

The item content validity index (I-CVI) and averaging calculation method(S-CVI/Ave) were used to evaluate the content validity [33]. Nine experts, including two psychological professors, one doctor, two advanced nurse practitioners and four associate professors in nursing, were invited to score and to evaluate item validity of the MBSS using clarity of phrasing and applicability of content as criteria [34]. Simultaneously, the experts gave suggestions on item modification and evaluated correlation level of each item for its corresponding construct using 4-point scale (from not relevant to highly relevant). According to nine experts' responses and comments, the I-CVI of item 1 and 18 was 0.67 , and item 24, 25, 26 were 0.44 , with experts' comments of inappropriateness due to cultural diversity, which should be candidates for deletion [33]. Therefore, we deleted the five items with the value of I-CVI below 0.78. The I-CVI of remaining items ranged from 0.78 to 1 and the S-CVI/Ave was 0.95 , indicating an adequate content validity of the 27 -item version C-MBSS.

\section{Sample}

More accurate solutions are achieved with larger sample sizes rather than the ratio of participants to variables of 1:5 to $1: 10$ [35]. Therefore, the item to participant ratio of 1:20 was used to calculate sample size. Considering possible data loss, we included more participants. Inclusion criteria were:(1) over 18 years old;(2) Having normal communication and literacy skills;(3) Voluntary participation. Participants with mental disorder or poor physical condition were excluded. Before the survey, participants received a brief introduction about the study and how to finish the questionnaire. All participants' information were assured to keep confidentially and verbal informed consent was obtained before data collection. The sample included 100 patients, 100 patients' caregivers, 750 university students, 550 medical staff. The researchers collected 1402 returned questionnaires. The return rate of questionnaires was $93.47 \%$. After screening, 59 questionnaires that were not fully completed were excluded. Therefore, a total of 1343 questionnaires were returned for analyzed; The valid return rate was $95.79 \%$.

Loading [MathJax]/jax/output/CommonHTML/jax.js 


\section{Statistical analysis}

Data base were established by Epidata 3.1 and then imported into Statistical Package for the Social Sciences version 20.0 (SPSS 20.0). Demographic data were analyzed using descriptive statistics. The validity and reliability of the C-MBSS were analyzed using SPSS 20.0 and Analysis of Moment Structure version 24 (AMOS 24). Firstly, factor analysis including exploratory factor analysis (EFA) and confirmatory factor analysis (CFA) were used to test the construct validity of the C-MBSS. The 1343 sample was divided into groups A and B randomly using SPSS 20.0. Sub-sample $A(n=672)$ was used for EFA. Kaiser-Meyer-Olkin(KMO) and Bartlett's test of sphericity were used to test sampling adequacy and the suitability of data for factorisation respectively. Monte Carlo parallel analysis was used to extract factor number. Principal axis factoring with direct oblimin rotationwas used to identify meaningful components [35, 36]. According to stevens' advice [37], a sample size of 600 with a loading of 0.21 can be considered significant. Therefore,we deleted items with factor loads below 0.21 or cross-factor loads over 0.21 . Sub-sample $B(n=671)$ were used for CFA to verify the factor structure of the C-MBSS derived from EFA. In the study, model fit was reflected by six fit indices including CMIN/DF, GFI, AGFI, CFI, RMSEA, SRMR [38]. Secondly, The Cronbach`s a coefficient was used to assess internal consistency reliability, and acceptable level should be greater than 0.6 [39].

\section{Results}

\section{Demographic characteristics}

Of the 1343 participants who submitted eligible questionnaires, 655(48.77\%) were university students, 491(36.56\%) were medical staff, and 197(14.67\%) were patients receiving percutaneous coronary intervention and their caregivers. A total of $222(16.53 \%)$ were male and $1121(83.47 \%)$ were female. The age ranged from 18 to 82 years old with an average age of 27.97 years. $1074(80 \%)$ were of Han nationality and $269(20 \%)$ belonged to minority nationality. Among the participants, 65(4.84\%) had master degree or above, 1089(81.09\%) had baccalaureate degree, 189(14.07\%) had associate degree or below.

\section{Exploratory factor analysis}

The C-MBSS is consisted of four hypothetical stress-evoking scenarios and theoretically the responses for each scenario are categorized into two factors, thus, we performed exploratory factor analysis to explore factor structures in each scenario. The Kaiser-Meyer-Olkin(KMO) for each scenario exceeded 0.5 and all Bartlett's tests of sphericity were statistically significant $(p=.000)$, which supported the use of factor analysis [40]. The parallel analysis resulted in 2-factor assumption for scenario 2, scenario 3 and scenario 4, and resulted in 3-factor assumption for scenario 1. According to the result of principal axis factoring and direct oblimin rotation, item2 in scenario 1 was deleted because of factor loading lower than 0.21 . The left 6 items in scenario 1 were re-performed EFA. The value of KMO and Bartlett's tests of sphericity met target level. The parallel analysis resulted in 2-factor assumption for scenario 1 and the factor loadings of all items met requirements. The variance explained in each scenario ranged from 43.98-52.99\%. Table 1 shows the rotated factor loadings of the item. 
Item

Factor

Variance

Loadings

explained

\section{Scenario 1}

Factor 1: monitoring

$27.97 \%$

4. I would want the dentist to tell me when I would feel pain.

0.33

6. I would watch all the dentist's movements and listen for the sound of

0.66

the drill.

7. I would watch the flow of water from my mouth to see if it contained blood.

0.76

Factor 2: blunting

$25.02 \%$

3. I would try to think about pleasant memories.

0.45

5. I would try to sleep.

0.54

8. I would do mental puzzles in my mind.

0.50

\section{Scenario 2}

Factor 1: monitoring

10. I would stay alert and try to keep myself from falling asleep.

0.51

12. If there was a radio present, I would stay near it and listen to the bulletins about what $\quad 0.52$ the police were doing.

13. I would watch every movement of my captors and keep an eye on their weapons. $\quad 0.59$

16. I would make sure I knew where every possible exit was.

0.52

\section{Factor 2: blunting}

9. I would sit by myself and have as many daydreams and fantasies as I could.

0.34

11. I would exchange life stories with the other hostages.

0.46

14. I would try to sleep as much as possible.

0.31

15. I would think about how nice it's going to be when I get home.

0.50

\section{Scenario 3}

Factor 1: monitoring

$29.08 \%$

17. I would talk to my fellow workers to see if they knew anything about what the 0.65 supervisor evaluation of me said.

20. I would try to remember any arguments or disagreements I might have had that would $\quad 0.54$ have resulted in the supervisor having a lower opinion of me.

23. I would try to think which employees in my department the supervisor might have $\quad 0.52$ thought had done the worst job.

Factor 2: blunting

$21.37 \%$

19. I would go to the movies to take my mind off things. 
22. I would tell my spouse that l'd rather not discuss my chances of being

laid off.

\section{Scenario 4}

Factor 1: monitoring

28. I would call for the flight attendant and ask what exactly the problem

0.60

was.

30. I would listen carefully to the engines for unusual noises and would watch the crew to

0.46

see if their behavior was out of the ordinary.

31. I would talk to the passenger beside me about what might be wrong.

0.68

Factor 2: blunting

$20.96 \%$

27. I would watch the end of the movie, even if I had seen it before.

0.47

29. I would order a drink from the flight attendant or take a tranquilizer.

0.38

32. I would settle down and read a book or magazine or write a letter.

0.44

\section{Confirmatory factor analysis}

AMOS was used to construct a structural equation modelling with maximum likelihood to verify the 2-factor hypothesis in each scenario extracted from EFA. Table 2 presents the CFA fit indices for the four scenarios. These indices showed moderately good fit for the models and provided confirmatory evidence for the factor structure in the four scenarios [41, 42].

Table 2

Fit indices for confirmatory factor analysis of the four scenarios

\begin{tabular}{|lllllll|}
\hline Scenario & CMIN/DF & GFI & AGFI & CFI & RMSEA & SRMR \\
\hline Scenario 1 & 2.775 & 0.989 & 0.972 & 0.968 & 0.051 & 0.0395 \\
\hline Scenario 2 & 5.466 & 0.962 & 0.927 & 0.810 & 0.082 & 0.0630 \\
\hline Scenario 3 & 6.329 & 0.976 & 0.937 & 0.829 & 0.089 & 0.0598 \\
\hline Scenario 4 & 3.588 & 0.986 & 0.964 & 0.920 & 0.062 & 0.0409 \\
\hline $\begin{array}{l}\text { CMIN/DF = chi-square/degrees of freedom; GFI = goodness-of-fit index; AGFI = adjusted goodness of fit index; CFI = } \\
\text { comparative fit index; RMSEA = root mean square error of approximation; SRMR = standardized root mean square } \\
\text { residual. }\end{array}$
\end{tabular}

When we performed factor analysis, we found that factor 1 in scenario 1, factor 1 in scenario 2, factor 1 in scenario 3 and factor 1 in scenario 4 were strongly correlated, similarly, factor 2 in scenario 1, factor 2 in scenario 2, factor 2 in scenario 3 and factor 2 in scenario 4 were strongly correlated (seen in Fig. 1), which suggested that there existed second-order latent variables which might replace highly correlated factors to make the models more precise. Hence, we used the second-order CFA models to replace the first-order models. According to the research of Miller [19, 20], we assumed there were Monitoring and Blunting factors in the C-MBSS. The second-order models are shown in Fig. 2 and Fig. 3. In this study, the T value of Monitoring second-order CFA was 0.94, and Blunting second-order CFA was 0.97, which provided mananahln avidanan of a connnd_ardar wanrs satisfaction construct [43]. The model fit indices for Monitoring were: 
$\mathrm{CMIN} / \mathrm{DF}=2.253, \mathrm{GFI}=0.969, \mathrm{AGFI}=0.954, \mathrm{CFI}=0.931, \mathrm{RMSEA}=0.043, \mathrm{SRMR}=0.0429$, and the model fit indices for Blunting were: $\mathrm{CMIN} / \mathrm{DF}=2.861, \mathrm{GFI}=0.962, \mathrm{AGFI}=0.943, \mathrm{CFI}=0.813, \mathrm{RMSEA}=0.053, \mathrm{SRMR}=0.0489$, which indicated a good fit between theoretical model anddata $[41,42,44]$. Compared with the model fits of the four scenarios, these values provided confirmatory evidence for the second-order factor structure.

\section{Internalconsistencyreliability}

The results of internal consistency reliability tests showed that the Cronbach's alpha coefficient for the total scale was 0.66 , and for the monitoring sub-scale and blunting sub-scale were 0.75 and 0.62 respectively, which demonstrated acceptable internal reliability in both the instrument and the sub-dimensions $[45,46]$.

\section{Discussion}

Our study proved that the C-MBSS has good psychometric properties and is a proper, reliable and valid instrument to assess information-seeking style of Chinese population. Due to cultural differences, six items were deleted giving final total of 26 items in the Chinese version of MBSS. According to the experts, item 1, 18, 24, 25 and 26 were deleted resulting from unable to differentiate information-seeking style in the context of Chinese culture. Ideas about confucianism and collectivism are cherished and valued in Chinese culture. For the deletion of item 1,one plausible explanation is that Chinese patients are used to subordinate in the doctor-patient relationship and patient empowerment is not common [47]; therefore, most patients prefer to listen to the doctors rather than asking questions. Item 1 'I would ask the dentist exactly what work was going to be done.' might not suit Chinese health care background. The Confucian principle of hierarchy and obedience emphasize power and social ranking in the organizations of Chinese society [48, 49], which means the inferiors are used to be appraised by their superiors instead of by themselves, hence item 18 'I would review the list of duties for my present job and try to figure out if I had fulfilled them all.' seems inappropriate for Chinese population. In the face of being laid off, the loyal Chinese subordinates show their loyalty and dedication to the supervisors [49] and they will continue doing their work whatever happened; therefore for item24: 'I would continue doing my work as if nothing special was happening.', most of the people might choose to do so no matter what type of information-seeking style they belong. From childhood, Chinese people are trained not to disobey [48], so both monitoring and blunting type person might choose to read the safety notice card as required by the crew man, and the item 25 ' would carefully read the information provided about safety features in the plane and make sure I knew where the emergency exits were' might not identify the different information-seeking style. The collectivist culture emphasis on people instead of task. For example, people would pause and chat with their friends when meeting them on the way to work in the collectivist culture [50]. For item 26' I would make small talk with the passenger beside me', both the monitoring and blunting type person might choose to do so because of cultural characteristic. Item 2 was deleted in the EFA process due to low factor loading. For item 2 'I would take a tranquilizer or have a drink before going.', the reason for its deletion might due to the fact that Chinese patients don't have the habit of taking a tranquilizer or having a drink before seeing a doctor.

The C-MBSS is consisted of four hypothetical stress-evoking scenarios, hence, we performed EFA for each scenario separately. In the study, EFA of the C-MBSS for each scenario obtained a two-factor solution that explained $52.99 \%$, $43.98 \%, 50.45 \%$ and $51.9 \%$ respectively of the variance in the research. CFA was performed to verify the factor structures that were selected from EFA. The results demonstrated moderately model fit and provided confirmatory evidence for the factor structure. When we performed first-order analysis, we found strong correlations among the eight factors in the CMBSS, which suggested high-order latent variants. Based on researches of Miller, we performed a second-order CFA to simplify the model and resulted in 2-factor assumption(Monitoring and Blunting). The values of T, CMIN/DF, GFI, AGFI, CFI, RMSEA and SRMR demonstrated the acceptable model fitness and proved the feasible 2-factor solution.

Loading [MathJax]/jax/output/CommonHTML/jax.js 
In our study, the Cronbach's alpha coefficient of theC-MBSS and its 2 sub-scales were within acceptable limits( 0.66 for the C-MBSS, 0.75 for monitoring sub-scale and 0.62 for blunting sub-scale) which prove that monitoring sub-scale has more acceptable internal consistency compare with blunting sub-scale, which is consistent with Miller [20] and Rees`s [29] study.

Giving the finding above, the C-MBSS can be used to identify individuals

$\in f$ or mation - seek $\in$ gbehavi or sunderthreatevents. Ithasbeenprovedthea $<$ heducationmat $\chi n g \in \div$ al s preferred information seeking behavior will lead to many positive health outcomes, oppositely, health education inconsistent with information seeking behavior is not conducive to the physical and mental health of patients. Hence, the information seeking behavior of patients should be taken into consideration when assessing issues of information need and patient education [22]. After verifying the psychometric properties of the C-MBSS, interventions can be designed to tailor patents' information seeking behavior and improve the results of health education.

\section{Limitation}

There are several limitations that should be taken into consideration. Although we have included a large and diverse sample size, the generalization of our findings might be limited due to the use of convenience sampling. The participants were mainly recruited from the southwest of China and unable to represent all people in China. In addition, due to practical constraints, we did not test the convergent/divergent validity and test-retest reliability of the C-MBSS. The convergent/divergent validity and test-retest reliability may be conducted in the future research.

\section{Conclusions}

Our research examined the content validity, construct validity and internal consistency reliability of the C-MBSS among university students, medical staff, patients receiving percutaneous coronary intervention and their caregivers. We deleted six items due to weak in differentiate information-seeking style in the context of Chinese cultural, resulting in a 26-items C-MBSS, which showed good psychometric properties and is a valuable instrument to identify the patient's informationseeking style. By using theC-MBSS, medial staff can assess patients' information seeking behavior, and give them the information that is tailored to their information-seeking style, which can help individuals fare better(psychologically, behaviorally, and physically), and enhance the effect of health education in the end.

\section{Abbreviations}




\begin{tabular}{|ll|}
\hline Abbreviations & Full Name \\
\hline MBSS & Miller Behavioral Style Scale \\
\hline I-CVI & Chinese Version of Miller Behavioral Scale \\
\hline S-CVI/Ave & Item Content Validity Index \\
EFA & Averaging Scale Content Validity Index \\
\hline CFA & Exploratory Factor Analysis \\
\hline AMOS & Confirmatory Factor Analysis \\
CMIN/DF & Chi-square/Degrees of Freedom \\
\hline GFI & Goodness-of-Fit Index \\
\hline AGFI & Adjusted Goodness of Fit Index \\
\hline CFI & Comparative Fit Index \\
\hline RMSEA & Root Mean Square Error of Approximation \\
\hline SRMR & Standardized Root Mean Square Residual \\
\hline
\end{tabular}

\section{Declarations}

\section{Declarations}

\section{Ethics approval and consent to participate}

This study was approved by the Ethics Committee of the First Affiliated Hospital of Kunming Medical University. (2019) Ethical review L no. 26

\section{Consent for publication}

Not applicable

\section{Availability of data and materials}

All data generated or analysed during this study are included in this published article [and its supplementary information files].

\section{Competing interests}

The authors declare that they have no competing interests

\section{Funding}

This study was supported by Priority Union Foundation of Yunnan Provincial Science and Technology Department and Kunming Medical University [2018FE001(-218)].

\section{Authors' contributions}


QQZ analysis and interpretation of data, Drafting the manuscript, HML analysis and interpretation of data, YJB analysis and interpretation of data,QLH have made substantial contributions to conception and design,ALH revising the manuscript,MFY acquisition of data,YJW acquisition of data,WW have made substantial contributions to conception and design,LD analysis and interpretation of data,FM analysis and interpretation of data, Revising the manuscript, Given final approval of the version to be publish. All authors read and approved the final manuscript.

\section{Acknowledgements}

The authors thank the participants who voluntarily participated in this study and special thanks to Dr. Suzanne M. Miller for her permission to use the Miller Behavioral Style Scale.

\section{References}

1. Chan SS, Leung DY, Leung AY, et al. A nurse-delivered brief health education intervention to improve pneumococcal vaccination rate among older patients with chronic diseases: a cluster randomized controlled trial. Int J Nurs Stud. 2015;52(1):317-324.

2. Clarkesmith DE, Pattison HM, Lip GY, Lane DA. Educational intervention improves anticoagulation control in atrial fibrillation patients: the TREAT randomised trial. PLoS One. 2013;8(9):e74037.

3. Golaghaie F, Bastani F. Cross-cultural adaptation of a patient-based tool for evaluating the implementation of patient education in acute care settings. Patient Educ Couns. 2014;96(2):210-215.

4. Liu Z, Zhang MM, Li YY, Li LX, Li YQ. Enhanced education for bowel preparation before colonoscopy: A state-of-theart review. J Dig Dis. 2017;18(2):84-91.

5. Michetti P, Weinman J, Mrowietz U, et al. Impact of Treatment-Related Beliefs on Medication Adherence in ImmuneMediated Inflammatory Diseases: Results of the Global ALIGN Study. Adv Ther. 2017;34(1):91-108.

6. Zwikker $\mathrm{HE}$, van den Ende $\mathrm{CH}$, van Lankveld WG, et al. Effectiveness of a group-based intervention to change medication beliefs and improve medication adherence in patients with rheumatoid arthritis: a randomized controlled trial. Patient Educ Couns. 2014;94(3):356-361.

7. Moret L, Rochedreux A, Chevalier S, Lombrail P, Gasquet I. Medical information delivered to patients: discrepancies concerning roles as perceived by physicians and nurses set against patient satisfaction. Patient Educ Couns. 2008;70(1):94-101.

8. Ronco M, Iona L, Fabbro C, Bulfone G, Palese A. Patient education outcomes in surgery: a systematic review from 2004 to 2010. Int J Evid Based Healthc. 2012;10(4):309-323.

9. Kamat N, Rajan Mallayasamy S, Sharma P, Kamath A, Pai G. Effect of video-assisted patient education on compliance with therapy, quality of life, psychomorbidity, and cost of illness in irritable bowel syndrome. Postgrad Med. 2019;131(1):60-67.

10. Pellise F, Sell P. Patient information and education with modern media: the Spine Society of Europe Patient Line. Eur Spine J. 2009;18 Suppl 3:395-401.

11. Johansson K, Nuutila L, Virtanen H, Katajisto J, Salantera S. Preoperative education for orthopaedic patients: systematic review. J Adv Nurs. 2005;50(2):212-223.

12. Miller SM, Fang CY, Manne SL, Engstrom PF, Daly MB. Decision making about prophylactic oophorectomy among atrisk women: psychological influences and implications. Gynecol Oncol. 1999;75(3):406-412.

13. Miller SM, Mangan CE. Interacting effects of information and coping style in adapting to gynecologic stress: should the doctor tell all? J Pers Soc Psychol. 1983;45(1):223-236.

14. Truog, R.D. Patients and doctors - The evolution of a relationship. N Engl J Med. 2012;366(7):581-585.

Loading [MathJax]/jax/output/CommonHTML/jax.js

Page $11 / 16$ 
15. Deyirmenjian M, Karam N, Salameh P. Preoperative patient education for open-heart patients: a source of anxiety? Patient Educ Couns. 2006;62(1):111-117.

16. Montazeri A, Sajadian A. Do women read poster displays on breast cancer in waiting rooms? J Public Health (Oxf). 2004;26(4):355-358.

17. Miller SM, Mischel W, O'Leary A, Mills M. From human papillomavirus (HPV) to cervical cancer: psychosocial processes in infection, detection, and control. Ann Behav Med. 1996;18(4):219-228.

18. Doherty-Torstrick ER, Walton KE, Fallon BA. Cyberchondria: Parsing Health Anxiety From Online Behavior. Psychosomatics. 2016;57(4):390-400.

19. Miller SM. When is a little information a dangerous thing? Coping with stressful events by monitoring versus blunting. Coping and health. 1980:145-169.

20. Miller SM. Monitoring and blunting: validation of a questionnaire to assess styles of information seeking under threat. J Pers Soc Psychol. 1987;52(2):345-353.

21. Miller SM, Tagai EK, Wen KY, et al. Predictors of adherence to follow-up recommendations after an abnormal Pap smear among underserved inner-city women. Patient Educ Couns. 2017;100(7):1353-1359.

22. Miller SM. Monitoring versus blunting styles of coping with cancer influence the information patients want and need about their disease. Implications for cancer screening and management. Cancer. 1995;76(2):167-177.

23. Erturk EB, Unlu H. Effects of pre-operative individualized education on anxiety and pain severity in patients following open-heart surgery. Int J Health Sci (Qassim). 2018;12(4):26-34.

24. Kola S, Walsh JC, Hughes BM, Howard S. Matching intra-procedural information with coping style reduces psychophysiological arousal in women undergoing colposcopy. J Behav Med. 2013;36(4):401-412.

25. Williams MN, Jones LM. Validating a measure of children's monitoring-blunting coping styles in dental situations. Psychol Health Med. 2012;17(3):274-284.

26. Goldstein, J. M. The relationship between coping and avoiding behavior and response to fear-arousing propaganda. Journal of Abnormal Psychology. 1959;58(2):247-252.

27. Averill JR, Rosenn M. Vigilant and nonvigilant coping strategies and psychophysiological stress reactions during the anticipation of electric shock. Journal of Personality \& Social Psychology. 1972,23(1):128-141.

28. Sherman KA, Winch CJ, Koukoulis A, Koelmeyer L. The effect of monitoring 'processing style' on post-surgical neuropathic pain in women with breast cancer. Eur J Pain. 2015;19(4):585-592.

29. Rees CE, Bath PA. The psychometric properties of the Miller Behavioural Style Scale with adult daughters of women with early breast cancer: a literature review and empirical study. J Adv Nurs. 2000;32(2):366-374.

30. Miró J. Translation, validation, and adaptation of an instrument to assess the information-seeking style of coping with stress: The Spanish version of the Miller Behavioral Style Scale. Personality \& Individual Differences. 1997;23(5):909-912.

31. Van Zuuren FJ, Wolfs HM. Styles of information seeking under threat: Personal and situational aspects of monitoring and blunting. Personality \& Individual Differences.1991,12(2):141-149.

32. Sousa VD, Rojjanasrirat W. Translation, adaptation and validation of instruments or scales for use in cross-cultural health care research: a clear and user-friendly guideline. J Eval Clin Pract. 2011;17(2):268-274.

33. Polit DF, Beck CT, Owen SV. Is the CVI an acceptable indicator of content validity? Appraisal and recommendations. Res Nurs Health. 2007;30(4):459-467.

34. Vivienne Wu SF, Courtney M, Edwards H, McDowell J, Shortridge-Baggett LM, Chang PJ. Development and validation of the Chinese version of the Diabetes Management Self-efficacy Scale. Int J Nurs Stud. 2008;45(4):534-542.

35. Gaskin CJ, Happell B. On exploratory factor analysis: a review of recent evidence, an assessment of current practice, Loading [MathJax]/jax/output/CommonHTML/jax.js it J Nurs Stud. 2014;51(3):511-521. 
36. Field A. Discovering Statistics Using SPSS (third edition). 2009:1-857.

37. Rosenblad A. Applied Multivariate Statistics for the Social Sciences, Fifth Edition by James P. Stevens. International Statistical Review. 2009;77(3).

38. Jackson DL, Gillaspy JA, Purc-Stephenson R. Reporting practices in confirmatory factor analysis: an overview and some recommendations. Psychol Methods. 2009;14(1):6-23.

39. Health measurement scales: a practical guide to their development and use (5th edition). Aust N Z J Public Health. 2016;40(3):294-295.

40. Byrne D. Quantitative Research Methods in the Social Sciences (15 credits). 2020.

41. Bentler P, Bonett D. Significance Tests and Goodness-of-Fit in Analysis of Covariance Structures. Psychological Bulletin. 1980;88:588-606.

42. lacobucci D. Structural equations modeling: Fit Indices, sample size, and advanced topics. Journal of Consumer Psychology. 2010,20(1):90-98.

43. Marsh HW, Hocevar D. Application of confirmatory factor analysis to the study of self-concept: First- and higher order factor models and their invariance across groups. Psychological Bulletin. 1985,97(3):562-582.

44. Schreiber JB, Nora A, Stage FK, Barlow EA, King J. Reporting Structural Equation Modeling and Confirmatory Factor Analysis Results: A Review. The Journal of Educational Research. 2006,99(6):323-337.

45. Nunnally J, Bernstein I. Psychometric Theory. 1994.

46. Cronbach L. Coefficient Alpha and Internal Structure of Tests. Psychometrika. 1951;16:297-334.

47. Jiang S, Street RL, Jr. The effects of patient-centered communication, social capital, and internet use on patient empowerment: a cross-sectional study in China. Glob Health Promot. Dec 2019;26(4):33-43.

48. Lu XW, Chauhan A, Campbell C. Representations of Mental Health Among Middle-Aged Urban Chinese Men. Journal of Community \& Applied Social Psychology. 2015,25(5):384-399.

49. Su SF, Jenkins M, Liu PE. Nurses' perceptions of leadership style in hospitals: a grounded theory study. Journal of Clinical Nursing. 2012,21(1-2):272-280.

50. Triandis H, Bontempo R, Villareal M, Asai M, Lucca N. Individualism and Collectivism: Cross-Cultural Perspectives on Self-Ingroup Relationship. Journal of Personality and Social Psychology. 1988;54:323-338.

\section{Figures}




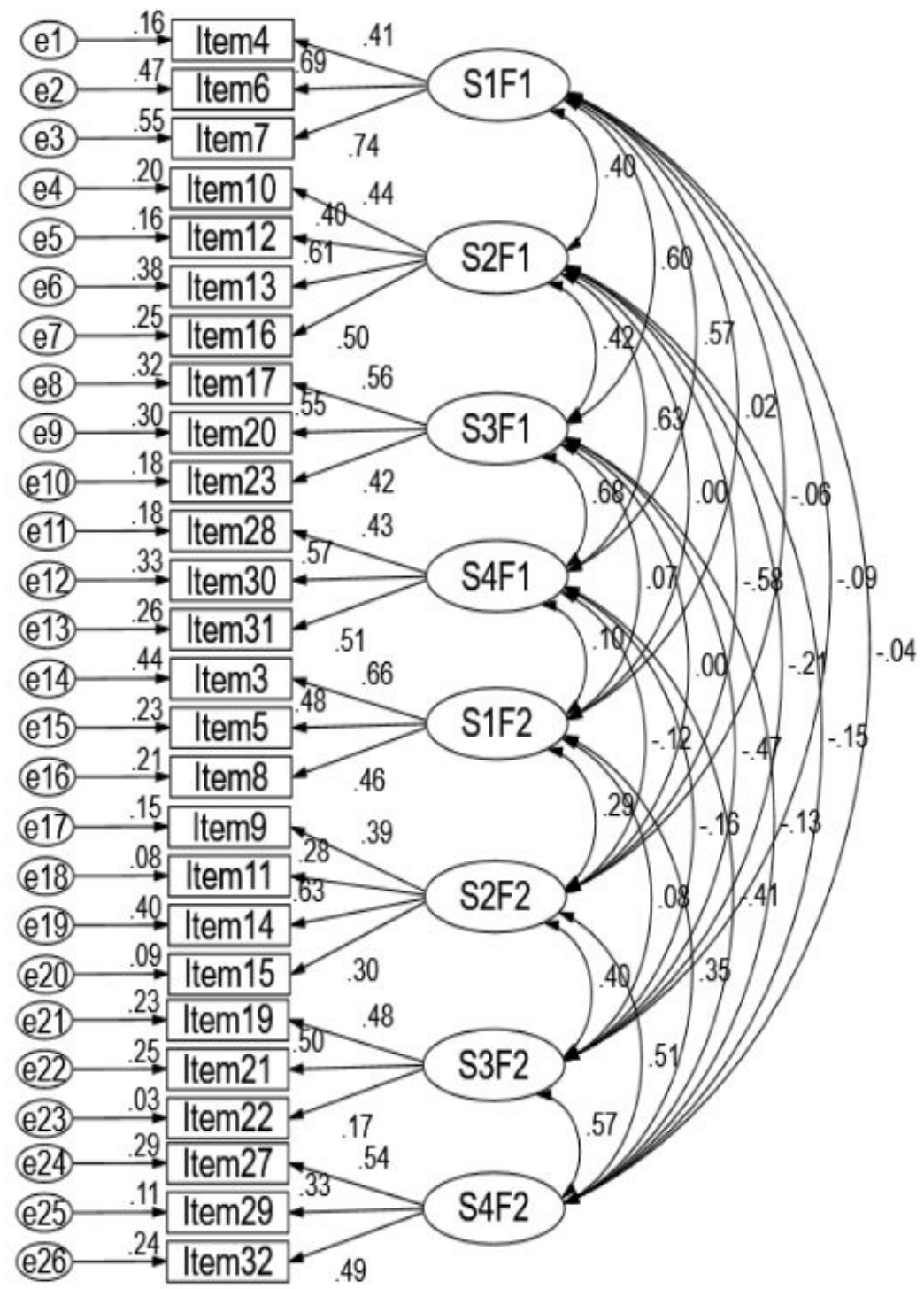

Figure 1

The correlations of the factors in four scenarios of the C-MBSS S1F1: scenario 1 factor 1, S2F1: scenario 2 factor 1 , S3F1: scenario 3 factor 1, S4F1: scenario 4 factor 1, S1F2: scenario 1 factor 2, S2F2: scenario 2 factor 2, S3F2: scenario 3 factor 2, S4F2: scenario 4 factor 2. 


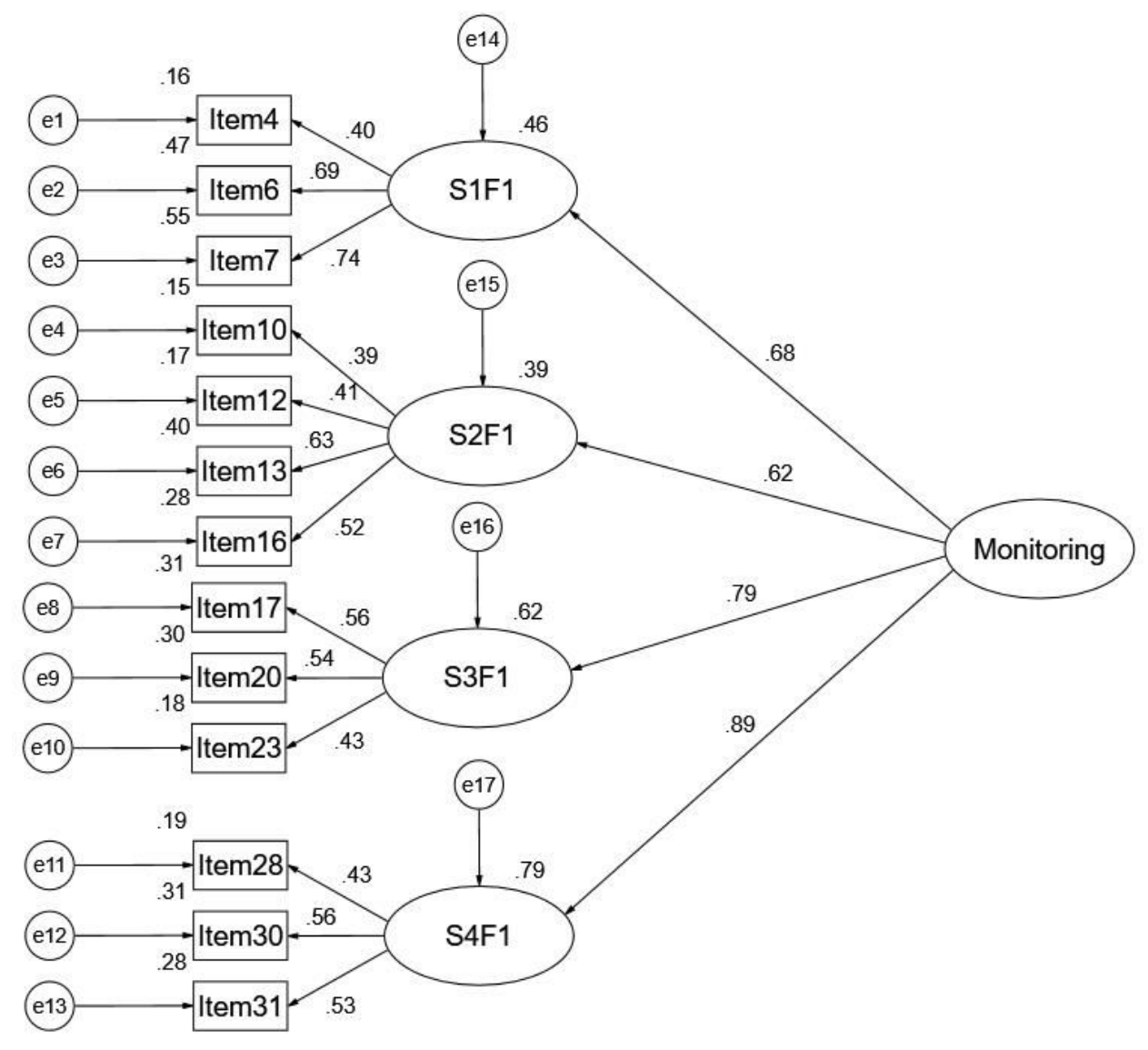

Figure 2

The second-order structural equation modelling of the factor structure of the Monitoring factor S1F1: scenario 1 factor 1 , S2F1: scenario 2 factor 1, S3F1: scenario 3 factor 1, S4F1: scenario 4 factor 1. 


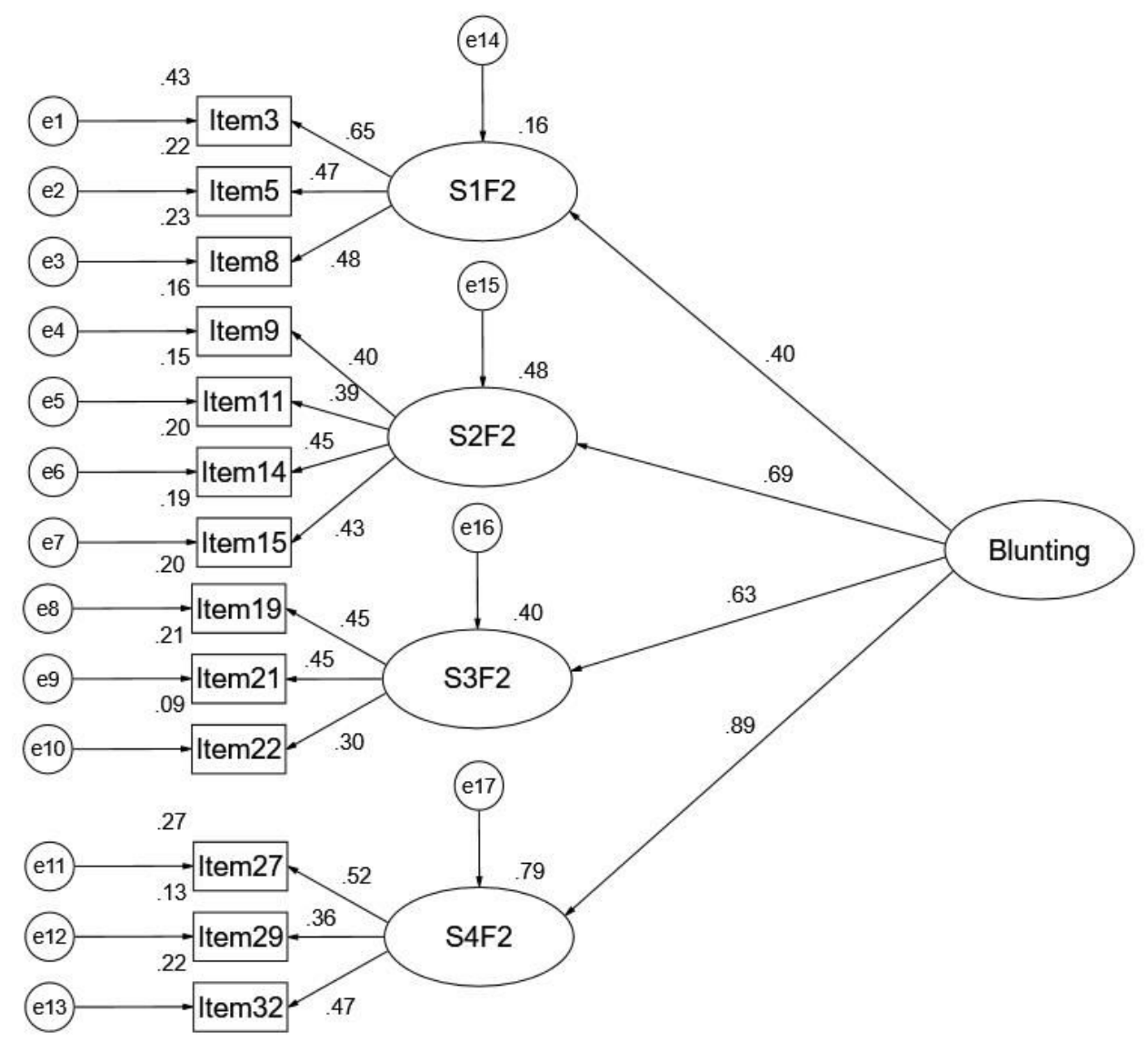

\section{Figure 3}

The second-order structural equation modelling of the factor structure of the Blunting factor S1F2: scenario 1 factor 2 , S2F2: scenario 2 factor 2, S3F2: scenario 3 factor 2, S4F2: scenario 4 factor 2.

\section{Supplementary Files}

This is a list of supplementary files associated with this preprint. Click to download.

- DatasubsamplesB.xls

- DatasubsamplesA.xls 